\title{
High STMN1 level is associated with chemo-resistance and poor prognosis in gastric cancer patients
}

Tuya Bai ${ }^{1}$, Takehiko Yokobori ${ }^{\star}{ }^{2}$, Bolag Altan ${ }^{3}$, Munenori Ide ${ }^{4}$, Erito Mochiki ${ }^{5}$, Mitsuhiro Yanai ${ }^{1}$, Akiharu Kimura ${ }^{1}$, Norimichi Kogure ${ }^{1}$, Toru Yanoma ${ }^{1}$, Masaki Suzuki ${ }^{1}$, Pinjie Bao ${ }^{1}$, Kyoichi Kaira ${ }^{3}$, Takayuki Asao ${ }^{6}$, Ayaka Katayama ${ }^{4}$, Tadashi Handa ${ }^{4}$, Navchaa Gombodorj ${ }^{7}$, Masahiko Nishiyama ${ }^{2,7}$, Tetsunari Oyama ${ }^{4}$, Kyoichi Ogata ${ }^{1}$ and Hiroyuki Kuwano ${ }^{1}$

${ }^{1}$ Department of General Surgical Science, Gunma University Graduate School of Medicine, Maebashi, Gunma 3718511, Japan; ${ }^{2}$ Research Program for Omics-based Medical Science, Division of Integrated Oncology Research, Gunma University Initiative for Advanced Research (GIAR), Maebashi, Gunma 3718511, Japan; ${ }^{3}$ Department of Oncology Clinical Development, Gunma University, Graduate School of Medicine, Maebashi, Gunma 3718511, Japan; ${ }^{4}$ Department of Diagnostic Pathology, Gunma University Graduate School of Medicine, Maebashi, Gunma 3718511, Japan; ${ }^{5}$ Department of Digestive Tract and General Surgery, Saitama Medical Center, Saitama Medical University, Kawagoe, saitama 3508550, Japan; ${ }^{6}$ Big Data Center for Integrative Analysis, Gunma University Initiative for Advance Research (GIAR), Maebashi, Gunma 3718511, Japan and ${ }^{7}$ Department of Molecular Pharmacology and Oncology, Gunma University, Graduate School of Medicine, Maebashi, Gunma 3718511, Japan

Background: Stathmin1 (STMN1) is a cytosolic phosphoprotein that regulates cellular microtubule dynamics and is known to have oncogenic activity. Despite several reports, its roles in gastric cancer (GC) remain unclear owing to a lack of analyses of highly metastatic cases. This study aimed to investigate STMN1 as a prognostic and predictive indicator of response to paclitaxel therapy in patients with GC, including inoperable cases.

Methods: Immunohistochemical analysis of STMN1 was performed on both operable $(n=95)$ and inoperable GC $(n=61)$ samples. The roles of STMN1 in cancer cell proliferation and sensitivity to a microtubule-targeting drug, paclitaxel, were confirmed by knockdown experiments using GC cell lines.

Results: Multivariate and Kaplan-Meier analyses demonstrated that high STMN1 was predictive of poor prognosis in both the groups. In the operable cohort, STMN1 expression correlated with cancer curability, recurrence, and resistance to adjuvant therapy. A correlation with paclitaxel resistance was observed in inoperable cases. Knockdown of STMN1 in GC cell lines inhibited proliferation and sensitised the cells to paclitaxel by enhancing apoptosis.

Conclusions: STMN1 is a possible biomarker for paclitaxel sensitivity and poor prognosis in GC and could be a novel therapeutic target in metastatic GC.

Gastric cancer (GC) is one of the most common malignancies globally, with approximately $989600(7.8 \%$ of the total) new cases and accounting for 738000 (9.7\% of the total) cancer-related deaths in 2008 (Jemal et al, 2011). Although the incidence of GC has been decreasing recently, its prognosis is generally poor with 5 -year relative survival below 30\% in most countries (Brenner et al, 2009). Surgery is the only curative treatment for patients with operable GC, and postoperative chemotherapy can improve the

*Correspondence: Dr T Yokobori; E-mail: bori45@gunma-u.ac.jp

Received 1 January 2017; revised 26 February 2017; accepted 1 March 2017; published online 23 March 2017

(C) 2017 Cancer Research UK. All rights reserved 0007-0920/17 
survival rate after surgery (Cao et al, 2014). However, most patients are not eligible for radical surgery because of locally advanced or metastatic disease (Sugano, 2008). Therefore, it is important to identify predictors of poor prognosis and new therapeutic targets for patients with refractory GC.

Stathmin1 (STMN1), also known as oncoprotein 18, is a promising molecular target in several cancers and an important cytoplasmic phosphoprotein that regulates cellular microtubule dynamics. STMN1 promotes microtubule depolymerisation by sequestering tubulin (Marklund et al, 1996; Rubin and Atweh, 2004; Budhachandra et al, 2008) and stimulating catastrophes (Howell et al, 1999). High STMN1 expression is associated with poor prognosis in a variety of human cancers such as nasopharyngeal carcinoma (Cheng et al, 2008; Hsu et al, 2014), distal oesophageal adenocarcinoma (Akhtar et al, 2014a), oesophageal squamous cell carcinoma (Akhtar et al, 2014b), breast cancer (Golouh et al, 2008), hepatocellular carcinoma (Hsieh et al, 2010), cholangiocarcinoma (Watanabe et al, 2014), prostate cancer (Mistry and Atweh, 2006), colorectal cancer (Wu et al, 2014), and non-small cell lung cancer (NSCLC; Nie et al, 2015). STMN1 was suggested as a possible prognostic marker and a potential therapeutic target for GC (Jeon et al, 2010; Kang et al, 2012; Ke et al, 2013). In these previous studies, the immunohistochemical analyses of STMN1 expression were all performed on operable (resected) GC specimens and not on inoperable cases including locally advanced cases and those with distant metastasis.

With the development of molecular targeting agents, improvement in patient outcomes is expected in many cancers; however, significant progress has not been achieved in developing targeted therapies for advanced GC (Wong and Yau, 2012; Lee et al, 2014). Conventional cytotoxic agents are still the foundation of the treatment for advanced cases and paclitaxel, a microtubuletargeting drug, is one of the key therapeutics.

In this study, we performed immunohistochemical tests on human specimens to clarify the clinical significance of STMN1 in GC patients, including, importantly, biopsy specimens of inoperable tumours. We also conducted STMN1 suppression analysis to determine the effects of STMN1 expression on the proliferation, chemotherapeutic sensitivity, and paclitaxel-induced apoptosis of GC cells. Our results suggest that STMN1 expression could be used to predict the prognosis and therapeutic response to paclitaxel and would be a novel therapeutic target.

\section{MATERIALS AND METHODS}

Clinical samples and cell lines. We used 156 GC samples collected from 95 operable GC cases (resected tumour specimens from 77 men and 18 women) and 61 inoperable GC cases (endoscopic biopsy specimens from 42 men and 19 women; inoperable status determined at initial diagnosis). Of the 95 operable GC patients, 35 were treated with S-1 (Taiho Pharmaceutical Co. Ltd.; Tokyo, Japan) and 14 were treated with 5-FUbased chemotherapy after surgery. Of the 61 inoperable patients, 39 were treated with paclitaxel + S- 1 and 22 were treated with cisplatin + S-1. S-1 (also known as TS-1) is one of the oral 5-FUbased anti-cancer drugs that combines tegafur, gimeracil, and potassium oxonate. The combination therapy of S-1 with cisplatin or paclitaxel is the standard regimen for inoperable GC patients in Japan (Mochiki et al, 2006; Satoh et al, 2011; Mochiki et al, 2012). All clinical GC samples were collected from Gunma University Hospital, Department of General Surgical Science between July 1999 to October 2011 and were used in accordance with the Helsinki Declaration and the guidelines of Gunma University Ethical Review Board for Medical Research Involving Human Subjects (approval number: 150044) after obtaining the written informed consent. The pathological features of the specimens were classified based on the 14th edition of the Japanese Classification of Gastric Carcinoma outlined by the Japanese Gastric Cancer Association. According to histology, the specimens were classified into differentiated type (well and moderately differentiated) and undifferentiated type (poorly differentiated and signet ring cells).

Human GC cell lines KATOIII, MKN7, MKN45 and MKN74 were maintained in RPMI 1640 containing 10\% foetal bovine serum (FBS) and supplemented with 100 units per ml penicillin and streptomycin sulphate, and were cultured in a humidified 5\% $\mathrm{CO}_{2}$ incubator at $37^{\circ} \mathrm{C}$.

Immunohistochemistry. Paraffin-embedded blocks of the specimens were cut into $2 \mu \mathrm{m}$-thick sections and mounted on glass slides. All sections were incubated at $60{ }^{\circ} \mathrm{C}$ for $60 \mathrm{~min}$ and deparaffinised in xylene, rehydrated, and then incubated with fresh $0.3 \%$ hydrogen peroxide in $100 \%$ methanol for $30 \mathrm{~min}$ at room temperature to block endogenous peroxidase activity. After rehydration through a graded series of ethanol treatments, antigen retrieval was performed using Immunosaver (Nishin EM, Tokyo, Japan) at $98-100{ }^{\circ} \mathrm{C}$ for $30 \mathrm{~min}$, and then the sections were passively cooled to room temperature. After rinsing in $0.1 \mathrm{M}$ phosphate-buffered saline (PBS, pH 7.4), sections were incubated in Protein Block Serum-Free Reagent (DAKO, Carpinteria, CA, USA) for $30 \mathrm{~min}$ to block non-specific binding sites. The sections were incubated overnight at $4{ }^{\circ} \mathrm{C}$ with mouse monoclonal antiSTMN1 (OP18) antibody (Santa Cruz Biotechnology, Santa Cruz, CA, USA) at a dilution of $1: 100$ in PBS containing $0.1 \%$ bovine serum albumin. The primary antibody was visualised using the Histofine Simple Stain MAX-PO (Multi) Kit (Nichirei, Tokyo, Japan) according to the manufacturer's instructions. chromogen 3,3-diaminobenzidine tetrahydrochloride was applied as a $0.02 \%$ solution in $50 \mathrm{mM}$ ammonium acetate-citrate acid buffer ( $\mathrm{pH} 6.0$ ) containing $0.005 \%$ hydrogen peroxide. The sections were lightly counterstained with haematoxylin and mounted. Negative controls were incubated without the primary antibody, and no detectable staining was evident.

STMN1 immunostaining was evaluated independently by two experienced researchers and using the method described by Altan et al (2013). The method was based on the intensity and percentage of cytoplasmic or nuclear stained cells. The intensity was scored as follows: 0 , no staining; $1+$, weak staining; $2+$, moderate staining; and $3+$, strong staining (Supplementary Figure 1 ). The percentage of stained cells was calculated by examining at least 1000 cancer cells in five representative areas and was scored as follows: 0 , no staining; $1+, 1-10 \% ; 2+, 11-50 \% ; 3+, 51-100 \%$. The final grading was calculated by multiplying the intensity score with the percentage score. The lower grades $(0,1,2,3$, and 4) were considered to be indicative of low expression, whereas the higher grades (6-9) were regarded indicating high expression.

Online microarray database search for STMN1 mRNA expression in GC. We used an online database KM plotter (www.kmplot.com) to validate the relevance of STMN1 mRNA expression to overall survival in patients with GC (Forster et al, 2011; Kim et al, 2012; Busuttil et al, 2014; Szasz et al, 2016). KM plotter is an entirely independent patient database, and a large scale survival data, which can be stratified by selected gene and characteristics including stage, Lauren classification, differentiation, gender, perforation, treatment, HER2 status, and data sets, can be available. We chose Affymetrix ID, 217714_x_at (STMN1), and investigated the prognostic value of STMN1 mRNA expression in 876 GC samples without above-mentioned characteristic restrictions. Auto select best cut-off value was used to identify the high and low groups. Overall survival data of 876 patients available were analysed by Kaplan-Meier survival curves (cut-off value was 361, and expression range of probe was 35-1473). 
Protein extraction and western blotting. Total protein was extracted from KATOIII, MKN7, MKN45, and MKN74 cells using PROPREP protein extraction solution (iNtRON Biotechnology, Sungnam, Kyungki-Do, Korea). Total proteins were separated by sodium dodecyl sulphate polyacrylamide gel electrophoresis (SDSPAGE) using Bis-Tris gels and were transferred to membranes by wet transfer. The membrane was blocked with 5\% skim milk and incubated overnight at $4{ }^{\circ} \mathrm{C}$ with anti-STMN1 rabbit monoclonal antibody ( $1: 1000$, Cell Signaling Technology, Danvers, MA, USA) and $\beta$-actin mouse monoclonal antibody $(1: 2000$, Sigma, St Louis, MO, USA). Bands on the membrane were detected with ECL Prime Western Blotting Detection Reagent using an Image Quant LAS4000 (GE Healthcare Life Sciences, Tokyo, Japan).

RNAi for down-regulation of STMN1. STMN1-specific siRNA oligos (STMN1 siRNA1; GAAACGAGAGCACGAGAAAtt: STMN1 siRNA2; CGAGACUGAAGCUGACUAAtt) and a nontargeting control siRNA oligos (NT siRNA) were purchased from Bonac Corporation (Fukuoka, Japan). MKN7 and MKN45 cell lines were seeded at $1 \times 10^{5}$ cells per well in a volume of $2 \mathrm{ml}$ in 6well flat-bottom plates and then incubated in a humidified atmosphere $\left(37^{\circ} \mathrm{C}\right.$ and $\left.5 \% \mathrm{CO}_{2}\right)$ for $24 \mathrm{~h}$. After incubation, $500 \mu \mathrm{l}$ of Opti-MEM I Reduced Serum Medium (Invitrogen), $5 \mu \mathrm{l}$ Lipofectamine RNAi MAX (Invitrogen) and STMN1 siRNA (50 $\mathrm{nM}$ final concentration in each well) were mixed and incubated for $20 \mathrm{~min}$. The siRNA reagents were then added to the cells. The RNA interference assay was conducted after $24 \mathrm{~h}$ incubation.

RNA extraction and quantitative reverse transcription polymerase chain reaction (RT-qPCR). Total RNA was extracted from cells using the miRNeasy Kit (Qiagen, Hilden, Germany), and the quantity of isolated RNA was measured with an ND-1000 spectrophotometer (Nano Drop Technologies, Wilmington, DE, USA). RT-qPCR was performed using the GoTaq 1-Step RT-qPCR System (Promega, Madison, WI, USA) according to the manufacturer's instructions. The program consisted of four stages: reverse transcription at $37^{\circ} \mathrm{C}$ for $15 \mathrm{~min}$, reverse transcriptase inactivation and hot-start activation at $95^{\circ} \mathrm{C}$ for $10 \mathrm{~min}, 40$ cycles of $95^{\circ} \mathrm{C}$ for $10 \mathrm{~s}, 60^{\circ} \mathrm{C}$ for $30 \mathrm{~s}$, and $72^{\circ} \mathrm{C}$ for $30 \mathrm{~s}$, and dissociation at $60-95^{\circ} \mathrm{C}$. The sequences of the primer pairs were as follows: STMN1 forward primer, 5'-AAGGATCTTTCCCTGGAGGA-3'; STMN1 reverse primer, 5'-CATTTGTGCCTCTCGGTTCT-3'; GAPDH forward primer, $5^{\prime}$-AAGGTGAAGGTCGGAGTCAAC-3'; GAPDH reverse primer, $5^{\prime}$-CTTGATTTTGGAGGGATCTCG- $3^{\prime}$.

Cell proliferation assay. Proliferation analysis of MKN7 and MKN45 cells treated with NT siRNA or STMN1 siRNA was performed. The cells were seeded in 96-well plates (approximately 3000 cells per well in $100 \mu \mathrm{l}$ of medium containing $10 \% \mathrm{FBS})$. After $0 \mathrm{~h}$, $24 \mathrm{~h}, 48 \mathrm{~h}$, and $72 \mathrm{~h}$, cell proliferation was measured with the Cell Counting Kit-8 (CCK-8; Dojindo Laboratories, Tokyo, Japan). Ten microliters of the cell counting solution was added to each well and incubated for $2 \mathrm{~h}$ at $37^{\circ} \mathrm{C}$. The absorbance of each well was determined using an Absorbance Spectrophotometer (Bio Rad, Hercules, CA, USA) at $450 \mathrm{~nm}$ with the reference wavelength set at $650 \mathrm{~nm}$.

Paclitaxel sensitivity assay. Paclitaxel sensitivity of cells treated with NT siRNA or STMN1 siRNA was measured. The cells were plated in 96-well plates at approximately 8000 cells per well with $100 \mu \mathrm{l}$ of medium, and after $24 \mathrm{~h}$ of incubation, the cells were treated with various concentrations of paclitaxel $(0,1.0,10,100$, and $1000 \mathrm{nM}$ ) for $48 \mathrm{~h}$. Cell viability was assessed using CCK-8
A

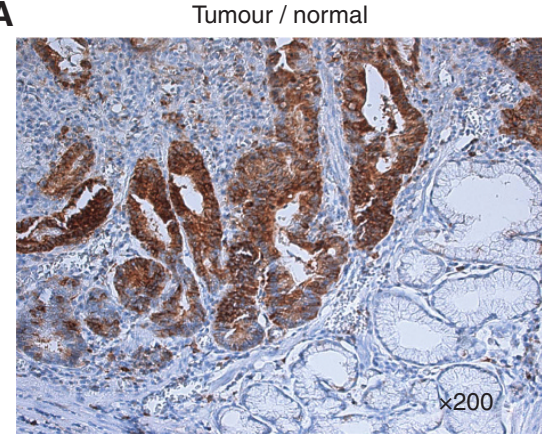

D

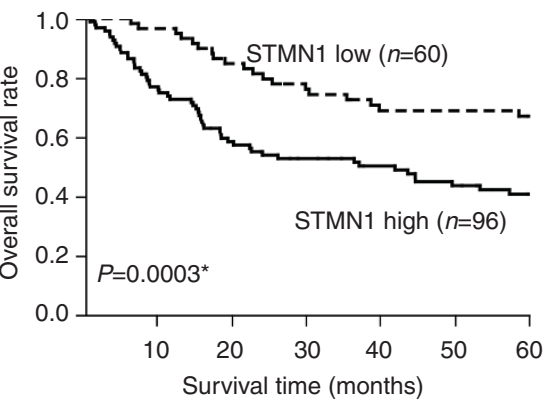

B STMN1 low expression

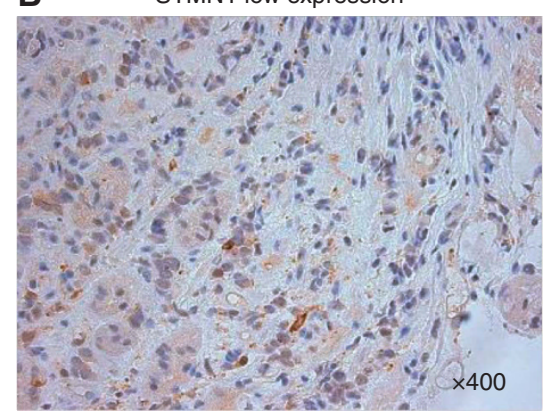

$\mathbf{E}$

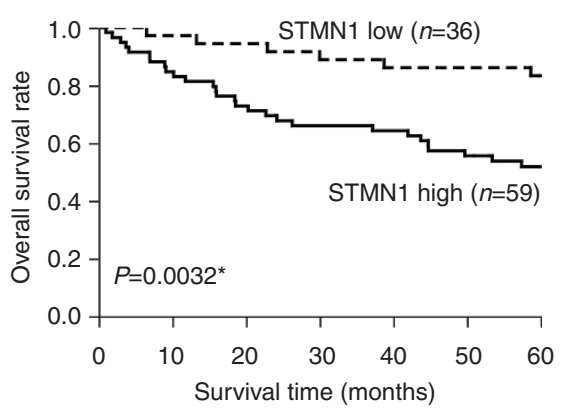

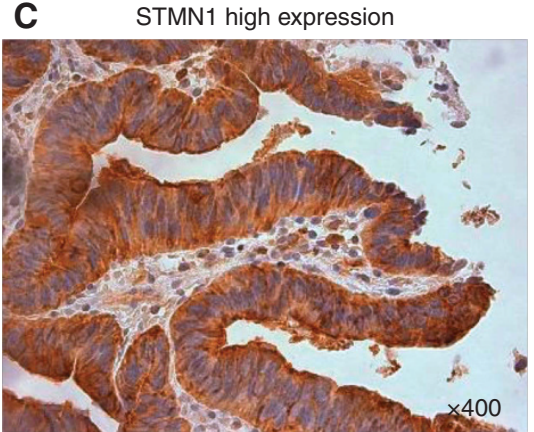

$\mathbf{F}$ Inoperable GC cohort $(n=61)$

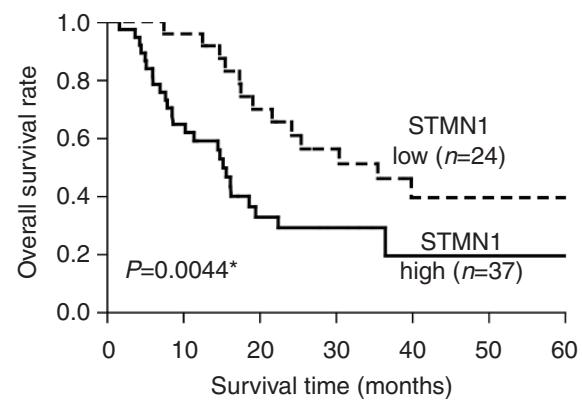

Figure 1. Immunohistochemical staining of STMN1 in GC samples. (A) Representative immunohistochemical staining of STMN1 in GC tissues (tumour) and normal gastric mucosa (normal; original magnification, $\times 200$ ). The expression level of STMN1 was stronger in GC tissues than in normal gastric mucosa. (B and C) Low and high expression of STMN1 in GC specimens (original magnification, $\times 400$ ). Sixty GC specimens (38.5\%) were classified into the low-STMN1-expression group and 96 (61.5\%) were assigned to the high-STMN1-expression group. (D) Kaplan-Meier overall survival in total GC cohort $(n=156)$; analyses were based on the expression of STMN1 $(P=0.0003)$. (E) Kaplan-Meier overall survival analyses of the operable GC cohort $(n=95)$ according to the expression level of STMN1 $(P=0.0032)$. (F) Kaplan-Meier overall survival analyses of the inoperable GC cohort $(n=61)$ according to the expression level of STMN1 $(P=0.0044)$. Kaplan-Meier overall survival rate in the high-STMN1expression group was significantly lower than that in the low-STMN1-expression group. 
(10 $\mu \mathrm{l}$ per well, for $2 \mathrm{~h}$ at $37^{\circ} \mathrm{C}$ ) and by measuring the absorbance of the medium at $450 \mathrm{~nm}$ with the reference wavelength set at $650 \mathrm{~nm}$ with an absorbance spectrophotometer (Bio Rad, Hercules, CA, USA). Paclitaxel was purchased from Sawai Pharmaceutical Co., Ltd.

Apoptosis assay. MKN7 and MKN45 cells treated with NT siRNA or STMN1 siRNA were seeded in 96-well plates. After $24 \mathrm{~h}$, paclitaxel was added (paclitaxel concentrations: 0, 1.0, 10, and $100 \mathrm{nM}$ ) to the cells and incubated for $48 \mathrm{~h}$. Paclitaxel-induced apoptosis was evaluated using the Amplite fluorometric Caspase-3/ 7 Assay Kit (AAT Bioquest) according to the manufacturer's instructions. Absorbance was read using the Enspire (Perkin Elmer) plate reader.

Statistical analysis. High-STMN1-expression group and lowexpression group in clinical GC samples were compared using the Wilcoxon test, the chi-squared test, and the repeated-measures
ANOVA. The Wilcoxon test was used to compare NT siRNA group with STMN1 siRNA group in in vitro analysis. KaplanMeier curves were generated for overall disease-free survival and statistical significance was determined using the log-rank test. Univariate and multivariate survival analyses were performed using Cox's proportional hazards model. A $P$-value of $<0.05$ was considered significant. All statistical analyses were performed using JMP software (SAS Institute Inc., Cary, NC, USA).

\section{RESULTS}

Immunohistochemical staining for STMN1 in GC specimens. We used immunohistochemistry to examine the expression of STMN1 in 156 GC specimens. The expression level of STMN1 was stronger in GC tissues (tumour) than in normal gastric mucosa (normal; Figure 1A). Among 156 GC cases, 60 (38.5\%) GC

Table 1. Clinical factors and STMN1 expression from GC patients

Clinical factors $\quad$ Total GC cohort $(n=156) \quad \square \quad$ Resected GC cohort $(n=95) \quad \square$ Unresectable GC cohort $(n=61)$

\begin{tabular}{|c|c|c|c|c|c|c|c|c|c|}
\hline & Low $n=60$ & High $n=96$ & $P$-value & Low $n=36$ & High $n=59$ & $P$-value & Low $n=24$ & High $n=37$ & $P$-value \\
\hline Age & $64.4 \pm 9.5$ & $63.5 \pm 10$ & 0.7804 & $63 \pm 9.4$ & $65 \pm 8.2$ & 0.403 & $63.5 \pm 10$ & $65 \pm 10$ & 0.562 \\
\hline $\begin{array}{l}\text { Gender } \\
\text { Male } \\
\text { Female }\end{array}$ & $\begin{array}{l}44 \\
16\end{array}$ & $\begin{array}{l}75 \\
21\end{array}$ & 0.4956 & $\begin{array}{c}28 \\
8\end{array}$ & $\begin{array}{l}49 \\
10\end{array}$ & 0.524 & $\begin{array}{c}16 \\
8\end{array}$ & $\begin{array}{l}26 \\
11\end{array}$ & 0.7672 \\
\hline $\begin{array}{l}\text { Histology type } \\
\text { Well, moderate } \\
\text { Poor, signet }\end{array}$ & $\begin{array}{l}33 \\
27\end{array}$ & $\begin{array}{l}45 \\
51\end{array}$ & 0.3231 & $\begin{array}{l}19 \\
17\end{array}$ & $\begin{array}{l}31 \\
28\end{array}$ & 0.9822 & $\begin{array}{l}14 \\
10\end{array}$ & $\begin{array}{l}14 \\
23\end{array}$ & 0.1164 \\
\hline $\begin{array}{l}\text { Tumour Depth } \\
\text { m, sm } \\
\text { mp, ss } \\
\text { se, si }\end{array}$ & $\begin{array}{l}12 \\
20 \\
28\end{array}$ & $\begin{array}{l}10 \\
33 \\
53\end{array}$ & 0.2388 & $\begin{array}{c}12 \\
17 \\
7\end{array}$ & $\begin{array}{l}10 \\
28 \\
21\end{array}$ & 0.1003 & $\begin{array}{c}0 \\
3 \\
21\end{array}$ & $\begin{array}{c}0 \\
5 \\
32\end{array}$ & 0.9086 \\
\hline $\begin{array}{l}\text { Lymph node } \\
\text { metastasis } \\
\text { Absent } \\
\text { Present }\end{array}$ & $\begin{array}{l}28 \\
32\end{array}$ & $\begin{array}{l}40 \\
56\end{array}$ & 0.5404 & $\begin{array}{l}18 \\
18\end{array}$ & $\begin{array}{l}27 \\
32\end{array}$ & 0.6883 & $\begin{array}{c}2 \\
22\end{array}$ & $\begin{array}{c}3 \\
34\end{array}$ & 0.975 \\
\hline $\begin{array}{l}\text { Liver metastasis } \\
\text { Absent } \\
\text { Present }\end{array}$ & $\begin{array}{c}56 \\
4\end{array}$ & $\begin{array}{c}90 \\
6\end{array}$ & 0.9179 & $\begin{array}{c}35 \\
1\end{array}$ & $\begin{array}{c}58 \\
1\end{array}$ & 0.7253 & $\begin{array}{c}21 \\
3\end{array}$ & $\begin{array}{c}32 \\
5\end{array}$ & 0.9086 \\
\hline $\begin{array}{c}\text { Peritoneal } \\
\text { metastasis } \\
\text { Absent } \\
\text { Present }\end{array}$ & $\begin{array}{c}51 \\
9\end{array}$ & $\begin{array}{l}76 \\
20\end{array}$ & 0.3568 & $\begin{array}{c}35 \\
1\end{array}$ & $\begin{array}{c}55 \\
4\end{array}$ & 0.3756 & $\begin{array}{c}16 \\
8\end{array}$ & $\begin{array}{l}21 \\
16\end{array}$ & 0.437 \\
\hline $\begin{array}{l}\text { Clinical stage } \\
\text { I } \\
\text { II } \\
\text { III } \\
\text { IV }\end{array}$ & $\begin{array}{c}24 \\
5 \\
13 \\
18\end{array}$ & $\begin{array}{l}24 \\
14 \\
17 \\
41\end{array}$ & 0.1218 & $\begin{array}{c}24 \\
5 \\
6 \\
1\end{array}$ & $\begin{array}{c}24 \\
14 \\
14 \\
7\end{array}$ & 0.0667 & $\begin{array}{c}0 \\
0 \\
7 \\
17\end{array}$ & $\begin{array}{c}0 \\
0 \\
3 \\
34\end{array}$ & $0.0314^{a}$ \\
\hline $\begin{array}{l}\text { First treatment } \\
\text { Sugery } \\
\text { chemotherapy }\end{array}$ & $\begin{array}{l}36 \\
24\end{array}$ & $\begin{array}{l}59 \\
37\end{array}$ & 0.856 & - & - & - & - & - & - \\
\hline $\begin{array}{l}\text { Surgical operation } \\
\text { Absent } \\
\text { Present }\end{array}$ & $\begin{array}{l}14 \\
46\end{array}$ & $\begin{array}{l}28 \\
68\end{array}$ & 0.4214 & - & - & - & $\begin{array}{l}14 \\
10\end{array}$ & $\begin{array}{c}28 \\
9\end{array}$ & 0.1554 \\
\hline $\begin{array}{l}\text { Curability } \\
\text { Curative } \\
\text { Non—curative }\end{array}$ & $\begin{array}{l}46 \\
14 \\
\end{array}$ & $\begin{array}{l}63 \\
33\end{array}$ & 0.1394 & $\begin{array}{c}36 \\
0\end{array}$ & $\begin{array}{c}54 \\
5\end{array}$ & $0.0264^{a}$ & $\begin{array}{l}10 \\
14\end{array}$ & $\begin{array}{c}9 \\
28\end{array}$ & 0.1554 \\
\hline $\begin{array}{l}\text { Recurrence } \\
\text { Absent } \\
\text { Present }\end{array}$ & 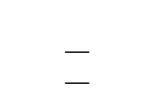 & - & - & $\begin{array}{c}28 \\
8\end{array}$ & $\begin{array}{l}26 \\
33\end{array}$ & $0.0001^{a}$ & - & - & - \\
\hline $\begin{array}{l}\text { Clinical response } \\
\text { PR } \\
\text { SD } \\
\text { PD }\end{array}$ & $\begin{array}{l}- \\
-\end{array}$ & $\begin{array}{l}- \\
-\end{array}$ & $\begin{array}{l}- \\
-\end{array}$ & $\begin{array}{l}- \\
-\end{array}$ & $\begin{array}{l}- \\
-\end{array}$ & $\begin{array}{l}- \\
-\end{array}$ & $\begin{array}{c}20 \\
2 \\
2\end{array}$ & $\begin{array}{c}20 \\
12 \\
5\end{array}$ & $0.0395^{a}$ \\
\hline
\end{tabular}


specimens were classified into the low-STMN1-expression group (Figure 1B) and $96(61.5 \%)$ were assigned to the high-STMN1expression group (Figure 1C).

Clinicopathological significance of STMN1 expression of GC. Kaplan-Meier analysis of data from 156 GC patients demonstrated that the overall survival rate in the high-STMN1-expression group was significantly lower than that in the low-STMN1-expression group (Figure 1D). This was found to be the case in both operable $(P=0.0032, n=95)$ and inoperable $(P=0.0044, n=61)$ cohorts, classified according to the initial diagnosis of the 156 patients (Figure $1 \mathrm{E}$ and $\mathrm{F}$ ). To confirm the prognostic significance of STMN1 expression in a large scale cohort, we used the KM plotter (www.kmplot.com), which includes published microarray data from 876 GC samples (Forster et al, 2011; Kim et al, 2012; Busuttil et al, 2014; Szasz et al, 2016). We validated that high expression of STMN1 in GC samples from a large database was associated with poor prognosis, the same as was found in our GC cohort $(\mathrm{HR}=1.47,95 \% \mathrm{CI}=1.22-1.77, P<0.05$, Supplementary Figure 2).

Unexpectedly, clinicopathological analyses of STMN1 expression in GC revealed no significant correlation among any of the investigated factors in the overall GC cohort (Table 1). Nevertheless, high expression of STMN1 in operable GC patients was found to be significantly associated with poor cancer curability $(P=0.0264)$ and recurrence $(P=0.0001)$, whereas in inoperable cases, this parameter was shown to relate to the progression of clinical stage $(P=0.0314)$ and poor clinical response against first-line chemotherapy $(P=0.0395$; Table 1$)$.

Uni- and multi-variate regression analyses for overall survival, using data from 156 GC samples, indicated that high expression of STMN1 was an independent factor for poor prognosis (univariate analysis: $\mathrm{RR}=2.49,95 \% \mathrm{CI}=1.52-4.25, \quad P=0.0002$; multivariate analysis: $\mathrm{RR}=2.79,95 \% \mathrm{CI}=1.65-4.91, P<0.0001)$ and was associated with

\section{Table 2. Univariate and multivariate analyses of overall survival in $156 \mathrm{GC}$ patients}

\begin{tabular}{|c|c|c|c|c|c|c|}
\hline \multirow[b]{2}{*}{ Clinicopathological variables } & \multicolumn{3}{|c|}{ Univariate analysis } & \multicolumn{3}{|c|}{ Multivariate analysis } \\
\hline & RR & $95 \% \mathrm{Cl}$ & $P$-value & RR & $95 \% \mathrm{Cl}$ & $P$-value \\
\hline \multicolumn{7}{|l|}{ Age } \\
\hline$\leq 65$ vs $>65$ & 1.03 & $0.65-1.62$ & 0.8976 & - & - & - \\
\hline \multicolumn{7}{|l|}{ Gender } \\
\hline Male vs female & 1.19 & $0.69-1.95$ & 0.5078 & - & - & - \\
\hline \multicolumn{7}{|l|}{ Histology type } \\
\hline Well, mod vs poor & 2.08 & $1.31-3.36$ & $0.0017^{a}$ & 1.79 & $1.129-2.92$ & $0.0137^{a}$ \\
\hline \multicolumn{7}{|l|}{ Tumour depth } \\
\hline SS vs SE, SI & 20.3 & $4.48-357.6$ & $<0.0001^{\mathrm{a}}$ & 10.3 & $2.14-186.9$ & $0.0011^{\mathrm{a}}$ \\
\hline \multicolumn{7}{|l|}{ Lymph node metastatic } \\
\hline Absent vs present & 1.97 & $1.22-3.25$ & $0.0048^{a}$ & 1.55 & $0.92-2.65$ & 0.0942 \\
\hline \multicolumn{7}{|l|}{ Peritoneal dissemination } \\
\hline Absent vs present & 3.32 & $1.94-5.51$ & $<0.0001^{\mathrm{a}}$ & 3.06 & $1.74-5.24$ & $0.0002^{a}$ \\
\hline \multicolumn{7}{|l|}{ Distant metastasis } \\
\hline Absent vs present & 2.65 & $1.15-5.28$ & $0.0232^{\mathrm{a}}$ & 2.01 & $0.86-4.14$ & 0.1022 \\
\hline \multicolumn{7}{|l|}{ STMN1 expression } \\
\hline Low vs high & 2.49 & $1.52-4.25$ & $0.0002^{a}$ & 2.79 & $1.65-4.91$ & $<0.0001^{a}$ \\
\hline
\end{tabular}

Table 3. Relationship between STMN1 expression and clinical factors (recurrence, clinical response)

\begin{tabular}{|c|c|c|c|c|c|c|}
\hline \multicolumn{7}{|c|}{ STMN1 expression and recurrence in operable GC treated by adjuvant therapy $(n=49)$} \\
\hline Recurrence & Low $(n=10)$ & ) $\quad$ High $(n=25)$ & $P$-value & Low $(n=5)$ & High $(n=9)$ & $P$-value \\
\hline Present & 5 & 21 & & 3 & 6 & \\
\hline Clinical response & Low $(n=13)$ & High $(n=26)$ & $P$-value & Low $(n=11)$ & High $(n=11)$ & $P$-value \\
\hline PR & 12 & 13 & $0.0141^{a}$ & 8 & 7 & 0.4836 \\
\hline SD & 1 & 9 & & 1 & 3 & \\
\hline PD & 0 & 4 & & 2 & 1 & \\
\hline
\end{tabular}


several cancer staging determinants, specifically, the histological type, tumour depth, and peritoneal dissemination (Table 2).

STMN1 expression and chemotherapeutic response. STMN1 is known to regulate cellular microtubule dynamics and its expression was confirmed to correlate with prognosis of GC patients. Based on these findings, we focused on the functional relevance of STMN1 to GC cellular sensitivity to chemotherapy, especially to paclitaxel treatment.

Of the 95 operable GC patients, 35 were treated with S-1 and 14 were treated with 5-FU-based medicine as an adjuvant therapy after the radical surgery. High STMN1 expression was significantly associated with a high recurrence rate $(P=0.044)$ and poor prognosis $(P=0.0214)$ in patients treated with $S-1$ after surgery (Table 3 and Figure 2A). These relationships, however, were not observed in patients treated with 5-FU-based adjuvant therapy (Table 3 and Figure 2B).

In the inoperable GC cohort $(n=61), 39$ patients were treated with paclitaxel + S- 1 and 22 were treated with cisplatin + S- 1 as first-line chemotherapy. High STMN1 expression correlated with poor clinical response $(P=0.0141$, Table 3$)$ and poor survival $(P=0.0082$, Figure $2 \mathrm{C})$ in the paclitaxel $+\mathrm{S}$-1-treated group $(n=39)$, but not in the cisplatin + S-1-treated group (Table 3 and Figure 2D).

Functional analysis of STMN1 in GC cell lines. We evaluated STMN1 expression in KATOIII, MKN7, MKN45, and MKN74 cell lines by western blotting (Figure 3A). We selected MKN7 and MKN45, which showed higher expression of the protein, for knockdown experiments to analyse the functional significance of STMN1 in proliferation and sensitivity to paclitaxel. siRNA was used to silence STMN1 and repression of the protein was confirmed by western blotting and RT-PCR (Figure 3B). Cell proliferation in the STMN1 siRNA groups was significantly suppressed compared to that in the NT siRNA groups and was closely associated with a decrease in STMN1 expression $(P<0.05$, Figure $3 \mathrm{C}$ ). Cell viability in the STMN1 siRNA group decreased significantly following paclitaxel treatment compared to the NT siRNA group $(P<0.05$, Figure 3D). Furthermore, paclitaxelinduced apoptosis in the STMN1 siRNA group was enhanced more than that of the NT siRNA group. Determination of caspase3/7 activities revealed that STMN1 knockdown enhanced paclitaxel-induced apoptosis. The number of apoptotic cells in the STMN1 siRNA groups after paclitaxel treatment was significantly higher than that in the other groups $(P<0.05$, Figure $3 \mathrm{E})$.

\section{DISCUSSION}

In this study, we showed that high STMN1 expression was associated with poor prognosis in 156 GC patients including both cohorts of 95 operable and 61 inoperable cases. Thirty-nine and 22 inoperable GC patients were treated with paclitaxel $+\mathrm{S}-1$ and cisplatin + S-1 combination therapies, respectively. We found that high STMN1 expression correlated to poor prognosis and poor response against chemotherapy in the paclitaxel $+\mathrm{S}-1$ treatment group, but this correlation was not observed in the cisplatin $+\mathrm{S}-1$
A

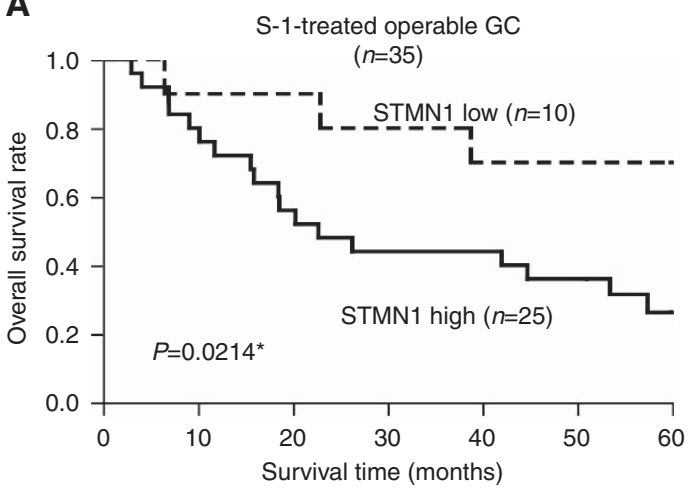

C

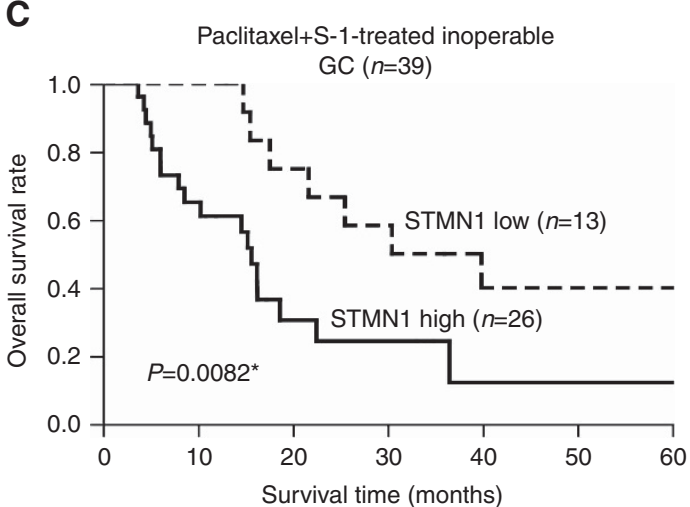

\section{B}

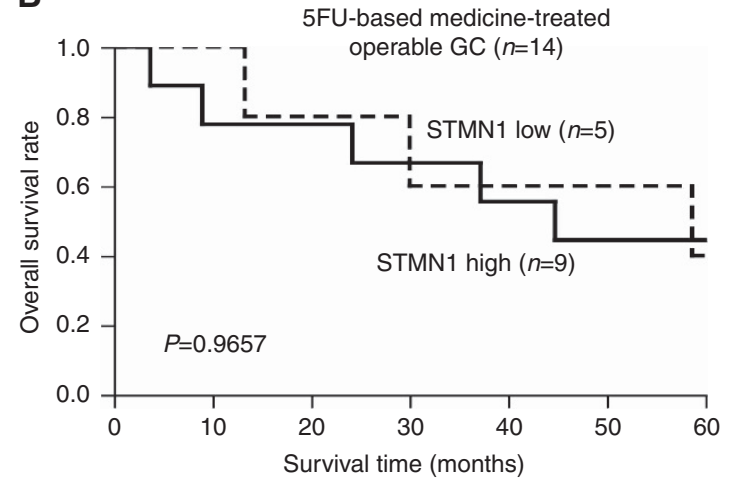

D

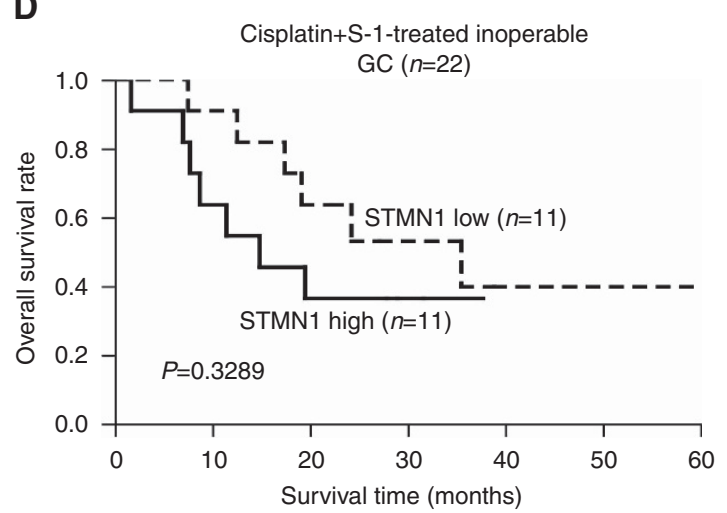

Figure 2. Overall survival curves of GC patients according to expression of STMN1. (A and B) Kaplan-Meier overall survival analyses of GC patients with operable tumours treated with S-1 and 5-FU-based medicine as adjuvant therapies after surgery. High STMN1 expression was significantly associated with poor prognosis in patients treated with S-1 after surgery $(P=0.0214)$. However, this relationship was not observed in patients treated with 5-FU-based adjuvant therapy $(P=0.9657)$. ( $C$ and $\mathbf{D})$ Kaplan-Meier overall survival analyses in patients with inoperable tumours treated with paclitaxel $+\mathrm{S}-1(P=0.0082)$ and cisplatin $+\mathrm{S}-1(P=0.3289)$ as first-line chemotherapy. High STMN1 expression correlated with poor survival in the paclitaxel $+\mathrm{S}$-1-treated group $(P=0.0082)$, but not in the cisplatin $+\mathrm{S}$-1-treated group $(P=0.3289)$. 
A

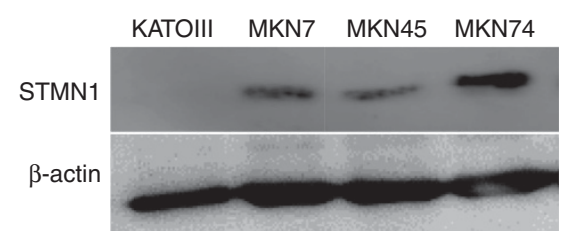

B
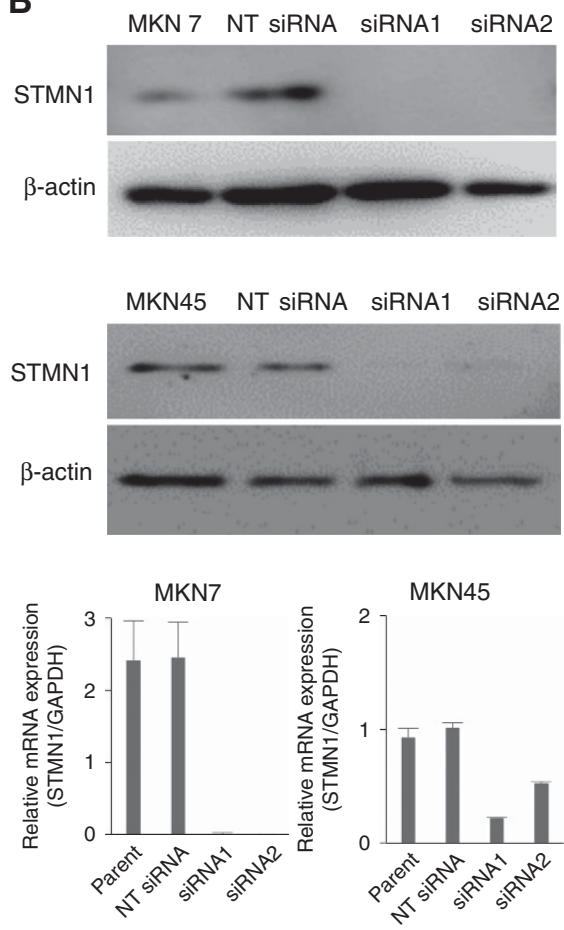
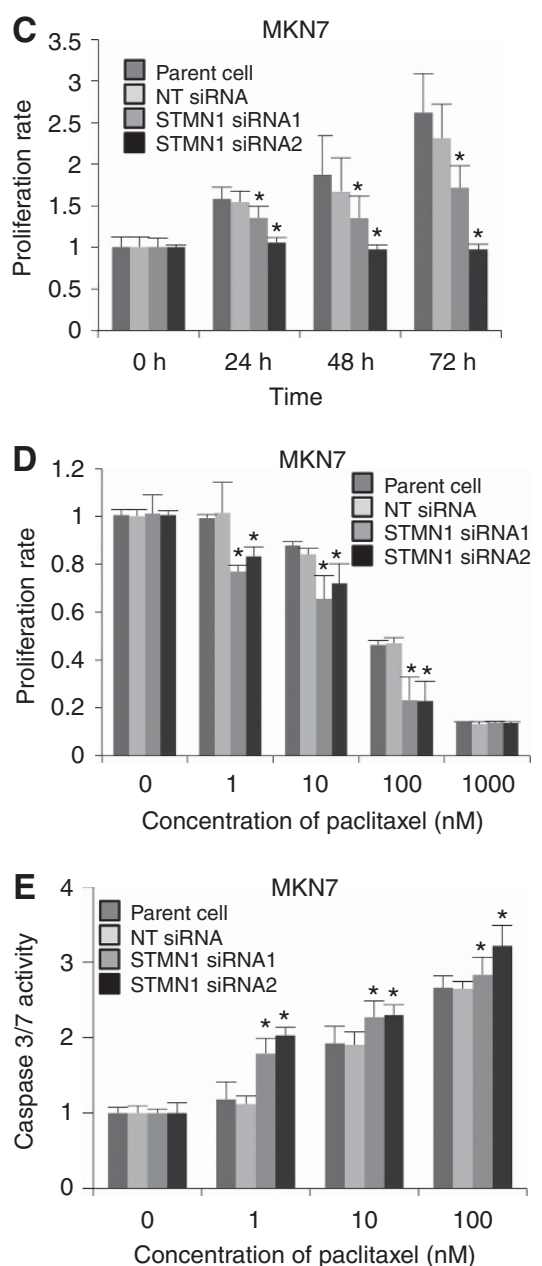
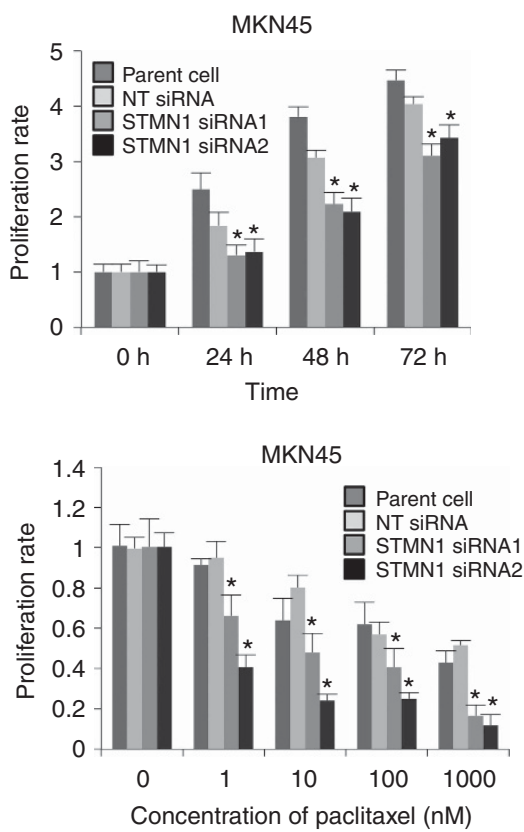

MKN45

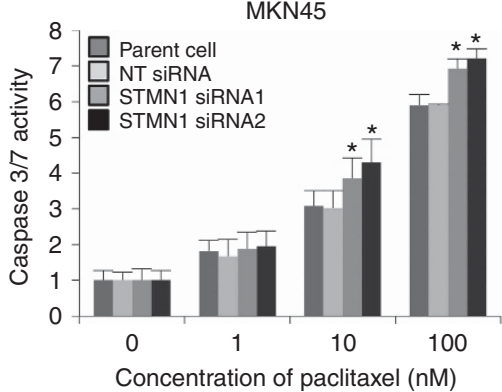

Figure 3. Functional analysis of human GC cell lines treated with STMN1 siRNA. (A) Expression of STMN1 was evaluated in GC cell lines KATOIII, MKN7, MKN45, and MKN74 by Western blotting. $\beta$-Actin was used as the loading control. (B) STMN1 expression in MKN7 and MKN45 cells treated with STMN1 siRNA1 or siRNA2 was detected by western blotting and RT-qPCR. STMN1 expression was suppressed in both STMN1 siRNA1 and siRNA2 groups. (C) Proliferation of MKN7 and MKN45 cells after STMN1 siRNA treatment was evaluated using Cell Counting Kit-8 kit. Cell proliferation in the STMN1 siRNA groups was significantly suppressed compared to that in the NT siRNA groups. (D) Paclitaxel sensitivity of MKN7 and MKN45 cells treated with STMN1 siRNA1 and siRNA2 was evaluated using Cell Counting Kit-8 kit. Cell viability in the STMN1 siRNA group decreased significantly following paclitaxel treatment compared to the NT siRNA group. (E) Paclitaxel-induced apoptosis in MKN7 and MKN45 cells treated with STMN1 siRNA1 and siRNA2 was evaluated by Amplite fluorometric Caspase-3/7 Assay Kit. Paclitaxel-induced apoptosis in the STMN1 siRNA group was enhanced more than that of the NT siRNA group.

treatment group. Moreover, multivariate analyses demonstrated that STMN1 expression was an independent prognostic factor in our cohorts. Our data suggests that STMN1 evaluation in GC tissues might be a useful marker for poor prognosis and chemosensitivity prediction.

In cancer patients, high STMN1 expression in tumours has already been reported to be associated with poor prognosis and more aggressive malignant potential than those with low STMN1 expression in tumours (Cheng et al, 2008; Golouh et al, 2008; Hsieh et al, 2010; Jeon et al, 2010; Kang et al, 2012; Ke et al, 2013; Hsu et al, 2014; Watanabe et al, 2014; Akhtar et al, 2014a; Akhtar et al, 2014b). These previous studies examined the significance of STMN1 expression only in resected cancer samples. On the other hand, our study evaluated the relationship between STMN expression, clinicopathological factors, and chemosensitivity in both resected GC samples and biopsy samples from inoperable GC patients. In this study, we clarified that high expression of STMN1 in the operable GC cohort was correlated with high recurrence rate after resection and advanced malignancy and high expression in the inoperable GC cohort correlated with advanced clinical stage and poor clinical response after chemotherapy. Our study is the first to demonstrate the possible clinical utility of STMN1 as a marker for both of operable and inoperable GC patients.

Wu et al (2014) reported that silencing STMN1 enhanced 5-FU sensitivity of colorectal cancer cells via a caspase-6-dependent mechanism. In addition, it was reported that STMN1 expression is related to the chemosensitivity to tamoxifen monotherapy in breast cancer (Golouh et al, 2008) and to platinum compounds and vinorelbine in NSCLC (Mlak et al, 2015). These observations suggest that STMN1 might be a drug sensitivity marker not only for taxane agents, but also for several conventional anti-cancer drugs. The association of high STMN1 expression with poor prognosis was observed in patients treated with $\mathrm{S}-1$, but not in patients who received 5-FU-based adjuvant therapy. The limited number of patients in these treatment groups might have contributed to the low detection power of STMN1 compared to that in the other studies of cancer marker genes.

Previous studies have examined the association between STMN1 expression and the response to taxane therapy, and a 
close association has been reported in ovarian cancer ( $\mathrm{Su}$ et al, 2009), breast cancer (Alli et al, 2002), lung cancer (Yuan et al, 2012), and endometrial cancer (Werner et al, 2014). While studying its functional mechanisms, Iancu et al (2001) found that inhibition of STMN1 expression in erythroleukaemia cells increased the ratio of polymerised tubulin and the sensitivity to paclitaxel. Alli et al (2002) also reported that overexpression of STMN1 decreased polymerisation of microtubules and decreased sensitivity to paclitaxel by binding to paclitaxel and inhibiting the G2 to M transition of cells. Consistent with these reports, we found that STMN1 knockdown increased paclitaxel sensitivity and paclitaxel-induced apoptosis and that high STMN1 expression was associated with poor prognosis in inoperable GC patients receiving a paclitaxel $+\mathrm{S}-1$ combination, but not in the cisplatin $+\mathrm{S}-1$ group. Our data suggest that STMN1 expression is a predictive marker of the clinical response to combination chemotherapy treatment including taxane agents.

Candidates for targeted therapy against refractory cancers are believed to express cancer-specific profiles. In this study, we examined the STMN1 expression profiles in normal human tissues using an RNA sequencing database (RefEx [http://refex.dbcls.jp]). Expression was detected in only the testis and cerebrum, and not in other vital organs (Supplementary Figure 3). Consistently, we and other researchers have also found that the expression of STMN1 in cancer tissues is higher than that in normal tissues and that it is associated with poor prognosis and cancer progression in several types of cancers (Curmi et al, 1999; Rana et al, 2008; Nie et al, 2015; Saito et al, 2016). Moreover, knockdown of STMN1 in cancer cells decreased proliferation and increased taxane-induced apoptosis. A targeting strategy of cancer-specific STMN1 expression could be a promising universal therapeutic tool against refractory cancers including GC with STMN1 accumulation.

In summary, STMN1 expression is associated with cancer progression and chemo-resistance in clinical GC samples. STMN1 expression might be a prognostic marker for GC. STMN1 was also shown to regulate the proliferation and paclitaxel sensitivity of GC cells. Our results suggest that STMN1 expression in GC might be a useful prognostic marker and a promising candidate for targeted therapy.

\section{ACKNOWLEDGEMENTS}

We thank Ms Yukie Saito, Ms Tomoko Yano, and Ms Yuka Matsui for their excellent assistance.

\section{CONFLICT OF INTEREST}

Masahiko Nishiyama received a research grant from Yakult Honsha Co. Ltd. Grants-in-Aid for Scientific Research from the Japan Society for the Promotion of Science (JSPS): grant numbers 26461969, 15K10129, and 15K10085. The work was supported in part by Uehara Zaidan, and Gunma University Initiative for Advanced Research (GIAR).

\section{REFERENCES}

Akhtar J, Wang Z, Yu C, Li CS, Shi YL, Liu HJ (2014a) STMN-1 is a potential marker of lymph node metastasis in distal esophageal adenocarcinomas and silencing its expression can reverse malignant phenotype of tumor cells. BMC Cancer 14: 28.

Akhtar J, Wang Z, Yu C, Zhang ZP, Bi MM (2014b) STMN-1 gene: a predictor of survival in stage iia esophageal squamous cell carcinoma after Ivor-Lewis esophagectomy? Ann Surg Oncol 21(1): 315-321.
Alli E, Bash-Babula J, Yang JM, Hait WN (2002) Effect of stathmin on the sensitivity to antimicrotubule drugs in human breast cancer. Cancer Res 62(23): 6864-6869.

Altan B, Yokobori T, Mochiki E, Ohno T, Ogata K, Ogawa A, Yanai M, Kobayashi T, Luvsandagva B, Asao T, Kuwano H (2013) Nuclear karyopherin-alpha2 expression in primary lesions and metastatic lymph nodes was associated with poor prognosis and progression in gastric cancer. Carcinogenesis 34(10): 2314-2321.

Brenner H, Rothenbacher D, Arndt V (2009) Epidemiology of stomach cancer. Methods Mol Biol 472: 467-477.

Budhachandra K, Brojen Singh RK, Menon GI (2008) Microtubule dynamics regulated by stathmin. Comput Biol Chem 32(2): 141-144.

Busuttil RA, George J, Tothill RW, Ioculano K, Kowalczyk A, Mitchell C, Lade S, Tan P, Haviv I, Boussioutas A (2014) A signature predicting poor prognosis in gastric and ovarian cancer represents a coordinated macrophage and stromal response. Clin Cancer Res 20(10): 2761-2772.

Cao J, Qi F, Liu T (2014) Adjuvant chemotherapy after curative resection for gastric cancer: a meta-analysis. Scand J Gastroenterol 49(6): 690-704.

Cheng AL, Huang WG, Chen ZC, Peng F, Zhang PF, Li MY, Li F, Li JL, Li C, Yi H, Yi B, Xiao ZQ (2008) Identification of novel nasopharyngeal carcinoma biomarkers by laser capture microdissection and proteomic analysis. Clin Cancer Res 14(2): 435-445.

Curmi PA, Gavet O, Charbaut E, Ozon S, Lachkar-Colmerauer S, Manceau V, Siavoshian S, Maucuer A, Sobel A (1999) Stathmin and its phosphoprotein family: general properties, biochemical and functional interaction with tubulin. Cell Struct Funct 24(5): 345-357.

Forster S, Gretschel S, Jons T, Yashiro M, Kemmner W (2011) THBS4, a novel stromal molecule of diffuse-type gastric adenocarcinomas, identified by transcriptome-wide expression profiling. Mod Pathol 24(10): 1390-1403.

Golouh R, Cufer T, Sadikov A, Nussdorfer P, Usher PA, Brunner N, Schmitt M, Lesche R, Maier S, Timmermans M, Foekens JA, Martens JW (2008) The prognostic value of Stathmin-1, S100A2, and SYK proteins in ER-positive primary breast cancer patients treated with adjuvant tamoxifen monotherapy: an immunohistochemical study. Breast Cancer Res Treat 110(2): 317-326.

Howell B, Larsson N, Gullberg M, Cassimeris L (1999) Dissociation of the tubulin-sequestering and microtubule catastrophe-promoting activities of oncoprotein 18/stathmin. Mol Biol Cell 10(1): 105-118.

Hsieh SY, Huang SF, Yu MC, Yeh TS, Chen TC, Lin YJ, Chang CJ, Sung CM, Lee YL, Hsu CY (2010) Stathmin1 overexpression associated with polyploidy, tumor-cell invasion, early recurrence, and poor prognosis in human hepatoma. Mol Carcinog 49(5): 476-487.

Hsu HP, Li CF, Lee SW, Wu WR, Chen TJ, Chang KY, Liang SS, Tsai CJ, Shiue YL (2014) Overexpression of stathmin 1 confers an independent prognostic indicator in nasopharyngeal carcinoma. Tumour Biol 35(3): 2619-2629.

Iancu C, Mistry SJ, Arkin S, Wallenstein S, Atweh GF (2001) Effects of stathmin inhibition on the mitotic spindle. J Cell Sci 114(Pt 5): 909-916.

Jemal A, Bray F, Center MM, Ferlay J, Ward E, Forman D (2011) Global cancer statistics. Cancer J Clin 61(2): 69-90.

Jeon TY, Han ME, Lee YW, Lee YS, Kim GH, Song GA, Hur GY, Kim JY, Kim HJ, Yoon S, Baek SY, Kim BS, Kim JB, Oh SO (2010) Overexpression of stathmin 1 in the diffuse type of gastric cancer and its roles in proliferation and migration of gastric cancer cells. Br J Cancer 102(4): $710-718$.

Kang W, Tong JH, Chan AW, Lung RW, Chau SL, Wong QW, Wong N, Yu J, Cheng AS, To KF (2012) Stathmin1 plays oncogenic role and is a target of microRNA-223 in gastric cancer. PLoS ONE 7(3): e33919.

Ke B, Wu LL, Liu N, Zhang RP, Wang CL, Liang H (2013) Overexpression of stathmin 1 is associated with poor prognosis of patients with gastric cancer. Tumour Biol 34(5): 3137-3145.

Kim HK, Choi IJ, Kim CG, Kim HS, Oshima A, Yamada Y, Arao T, Nishio K, Michalowski A, Green JE (2012) Three-gene predictor of clinical outcome for gastric cancer patients treated with chemotherapy. Pharmacogenomics J 12(2): 119-127.

Lee J, Kim KM, Kang WK, Ou SH (2014) Innovative personalized medicine in gastric cancer: time to move forward. Clin Genet 86(1): 37-43.

Marklund U, Larsson N, Gradin HM, Brattsand G, Gullberg M (1996) Oncoprotein 18 is a phosphorylation-responsive regulator of microtubule dynamics. EMBO J 15(19): 5290-5298.

Mistry SJ, Atweh GF (2006) Therapeutic interactions between stathmin inhibition and chemotherapeutic agents in prostate cancer. Mol Cancer Ther 5(12): 3248-3257. 
Mlak R, Krawczyk P, Ciesielka M, Homa I, Powrozek T, Prendecka M, Koziol P, Milanowski J, Malecka-Massalska T (2015) Predictive value of STMN1 gene promoter polymorphism $(-2166 \mathrm{~T}>\mathrm{C})$ in patients with advanced NSCLC treated with the combination of platinum compounds and vinorelbine. Cancer Chemother Pharmacol 76(3): 621-629.

Mochiki E, Ogata K, Ohno T, Toyomasu Y, Haga N, Fukai Y, Aihara R, Ando H, Uchida N, Asao T, Kuwano H. North Kanto Gastric Cancer Study G (2012) Phase II multi-institutional prospective randomised trial comparing S-1 + paclitaxel with S-1 + cisplatin in patients with unresectable and/or recurrent advanced gastric cancer. Br J Cancer 107(1): 31-36.

Mochiki E, Ohno T, Kamiyama Y, Aihara R, Haga N, Ojima H, Nakamura J, Ohsawa H, Nakabayashi T, Takeuchi K, Asao T, Kuwano H. North Kanto Gastric Cancer Study G (2006) Phase I/II study of S-1 combined with paclitaxel in patients with unresectable and/or recurrent advanced gastric cancer. Br J Cancer 95(12): 1642-1647.

Nie W, Xu MD, Gan L, Huang H, Xiu Q, Li B (2015) Overexpression of stathmin 1 is a poor prognostic biomarker in non-small cell lung cancer. Lab Invest 95(1): 56-64.

Rana S, Maples PB, Senzer N, Nemunaitis J (2008) Stathmin 1: a novel therapeutic target for anticancer activity. Expert Rev Anticancer Ther 8(9): 1461-1470.

Rubin CI, Atweh GF (2004) The role of stathmin in the regulation of the cell cycle. J Cell Biochem 93(2): 242-250.

Saito F, Araki K, Yokobori T, Ishii N, Tsukagoshi M, Watanabe A, Kubo N, Altan B, Shirabe K, Kuwano H (2016) High expression of karyopherinalpha2 and stathmin 1 is associated with proliferation potency and transformation in the bile duct and gall bladder epithelia in the cases of pancreaticobiliary maljunction. J Surg Oncol 114(4): 462-468.

Satoh S, Okabe H, Teramukai S, Hasegawa S, Ozaki N, Ueda S, Tsuji A, Sakabayashi S, Sakai Y. Kyoto University Surgical Oncology G (2011) Phase II trial report of preoperative chemotherapy (CX) with S-1 plus cisplatin for stage IV gastric cancer (StIV GC). J Clin Oncol 29(4_suppl): 107.

Su D, Smith SM, Preti M, Schwartz P, Rutherford TJ, Menato G, Danese S, Ma S, Yu H, Katsaros D (2009) Stathmin and tubulin expression and survival of ovarian cancer patients receiving platinum treatment with and without paclitaxel. Cancer 115(11): 2453-2463.

Sugano K (2008) Gastric cancer: pathogenesis, screening, and treatment. Gastrointest Endosc Clin N Am 18(3): 513-522, ix.

Szasz AM, Lanczky A, Nagy A, Forster S, Hark K, Green JE, Boussioutas A, Busuttil R, Szabo A, Gyorffy B (2016) Cross-validation of survival associated biomarkers in gastric cancer using transcriptomic data of 1065 patients. Oncotarget 7(31): 49322-49333.

Watanabe A, Suzuki H, Yokobori T, Tsukagoshi M, Altan B, Kubo N, Suzuki S, Araki K, Wada S, Kashiwabara K, Hosouchi Y, Kuwano H (2014) Stathmin1 regulates p27 expression, proliferation and drug resistance, resulting in poor clinical prognosis in cholangiocarcinoma. Cancer Sci 105(6): 690-696.

Werner HM, Trovik J, Halle MK, Wik E, Akslen LA, Birkeland E, Bredholt T, Tangen IL, Krakstad C, Salvesen HB (2014) Stathmin protein level, a potential predictive marker for taxane treatment response in endometrial cancer. PLoS ONE 9(2): e90141.

Wong H, Yau T (2012) Targeted therapy in the management of advanced gastric cancer: are we making progress in the era of personalized medicine? Oncologist 17(3): 346-358.

Wu W, Tan XF, Tan HT, Lim TK, Chung MC (2014) Unbiased proteomic and transcript analyses reveal that stathmin-1 silencing inhibits colorectal cancer metastasis and sensitizes to 5-fluorouracil treatment. Mol Cancer Res 12(12): 1717-1728.

Yuan S-F, Chen W-J, Zhu L-J, Zheng W-E, Chen H, Xiong J-P (2012) Effects of monoclonal antibodies against human stathmin combined with paclitaxel on proliferation of the QG-56 human lung carcinoma cell line. Asian Pac J Cancer Prev 13(6): 2967-2971.

This work is published under the standard license to publish agreement. After 12 months the work will become freely available and the license terms will switch to a Creative Commons AttributionNonCommercial-Share Alike 4.0 Unported License.

Supplementary Information accompanies this paper on British Journal of Cancer website (http://www.nature.com/bjc) 